\title{
Article
}

\section{New Graphene Composites for Power Engineering}

\author{
Tadeusz Knych, Andrzej Mamala, Paweł Kwaśniewski (D), Grzegorz Kiesiewicz, Beata Smyrak*(D), \\ Marek Gniełczyk, Artur Kawecki, Kinga Korzeń (D) and Eliza Sieja-Smaga
}

check for

updates

Citation: Knych, T.; Mamala, A.;

Kwaśniewski, P.; Kiesiewicz, G.;

Smyrak, B.; Gniełczyk, M.; Kawecki,

A.; Korzeń, K.; Sieja-Smaga, E. New

Graphene Composites for Power

Engineering. Materials 2022, 15, 715.

https://doi.org/10.3390/

ma15030715

Academic Editors: Anton Smirnov

and Antonio Di Bartolomeo

Received: 12 November 2021

Accepted: 15 January 2022

Published: 18 January 2022

Publisher's Note: MDPI stays neutral with regard to jurisdictional claims in published maps and institutional affiliations.

Copyright: (C) 2022 by the authors. Licensee MDPI, Basel, Switzerland. This article is an open access article distributed under the terms and conditions of the Creative Commons Attribution (CC BY) license (https:// creativecommons.org/licenses/by/ $4.0 /)$.

\author{
Non-Ferrous Metals Faculty, AGH University of Science and Technology, 30-059 Krakow, Poland; \\ tknych@agh.edu.pl (T.K.); amamala@agh.edu.pl (A.M.); kwas@agh.edu.pl (P.K.); gk@agh.edu.pl (G.K.); \\ mgmarkoni@gmail.com (M.G.); akawecki@agh.edu.pl (A.K.); kkorzen@agh.edu.pl (K.K.); \\ esmaga@agh.edu.pl (E.S.-S.) \\ * Correspondence: smyrak@agh.edu.pl
}

\begin{abstract}
Intensive research is underway worldwide to develop new conductive materials for applications in the power industry. Such tests aim to increase the electrical conductivity of materials for conductors and cables, thus increasing the current carrying capacity of the line and reducing the loss of electricity transmission. The scientific discovery of recent years, graphene, one of the allotropic types of carbon with very high electrical and thermal conductivity and mechanical strength, creates great opportunities for designing and producing new materials with above-standard operational properties. This project concentrates on developing technology for manufacturing aluminum-graphene and copper-graphene composites intended to be used to produce a new generation of power engineering conductors. In particular, we present the results of the research on the mechanical synthesis of aluminum-graphene and copper -graphene composites, as well as the results of the electric, mechanical, and structural properties of rods obtained after the extrusion process and wires after the drawing process.
\end{abstract}

Keywords: graphene; copper; aluminum; overhead conductors; composite

\section{Introduction}

Copper has high electrical conductivity $\left(58 \mathrm{MS} / \mathrm{m}\right.$ at $20^{\circ} \mathrm{C}$ ) and is widely used in electrical applications. Owing to a favorable ratio of mechanical strength to mass density and resistivity, aluminum is a conductive material competitive for copper and commonly used in power engineering, in particular in overhead power lines as ACSR (Aluminium Conductor Steel Reinforced) cables.

Continuously growing demand for higher transmission capacity of power lines is a driving force of the development of conductive materials engineering. Operating conditions of conductors impose additional requirements on conductive materials concerning strength and fatigue characteristics, rheology, and excellent corrosion resistance. It limits the application of pure metals, i.e., pure copper and pure aluminum, to produce power conductors and fosters the use of alloys that demonstrate high strength and are resistant to operating conditions. Consequently, electrical conductivity is reduced.

One of the dynamically developing directions of improving electric current transmission is superconductivity. Actually, the zero resistance, and consequently the lack of dissipation of electrical energy, mean superconductors are commonly used in the windings of superconducting electromagnets (e.g., in medicine, computed tomography, physics). The race to discover materials with an increasingly higher critical temperature, exceeding $100 \mathrm{~K}$, is still ongoing, e.g., 1988-YBaCuO (Tc $\approx 100 \mathrm{~K})$, 1995-HGBaCaCuO @ $30 \mathrm{GPa}(\mathrm{Tc} \approx 160 \mathrm{~K}$, $2000-\mathrm{MgB}_{2}(\mathrm{Tc} \approx 40 \mathrm{~K}), 2010-\mathrm{SrFFeAs}(\mathrm{Tc} \approx 60 \mathrm{~K}), 2010-\mathrm{FeS}(\mathrm{Tc} \approx 100 \mathrm{~K})$ and $2015-\mathrm{H}_{2} \mathrm{~S}$ @ $155 \mathrm{GPa}$ ( $\mathrm{Tc} \approx 200 \mathrm{~K}$ ). One of the latest discoveries is a $\mathrm{H}_{2} \mathrm{~S}$ superconducting material that obtains superconducting properties at a temperature of $200 \mathrm{~K}$ but at a high pressure 
of 155 GPa. Extremely low temperatures are no longer a requirement to generate superconductivity, and the discovery of superconducting materials operating at close to room temperature could find application in, for example, current transmission technology, where losses due to resistance in transmission lines could be almost completely avoided [1,2]. Another direction of research for improving the capacity of industrial lines is graphene. Graphene is a two-dimensional carbon material that has attracted great scientific and technological interest due to its intriguing physical properties and enormous potential for various applications [3-5]. All this has led to the development of rapidly evolving research within the field of graphene, based on the deposition of high quality and uniform thin films with controllable thickness over large areas.

Graphene has recently become a very attractive alternative as a new kind of "alloy additive" to copper and aluminum, allowing modification of their electrical and working characteristics. Unfortunately, concerning the low solubility of carbon in the metals, graphene is mainly used as a composite additive. Another mechanism of changing the electrical characteristics of the materials involves the formation of metal-carbon bonds called Covetic. Moreover, very high mechanical strength and the high melting point of graphene can positively affect the composite characteristics, increasing its resistance to operating conditions, including long-term temperature exposure-the parameter is closely related to the current-carrying capacity of power conductors.

Developing an effective graphene production technology and discovering its characteristics created new possibilities for making materials with non-standard characteristics. The greatest expectations concern the non-standard specific electrical conductivity of the materials. Table 1 presents selected physical characteristics of copper, graphene, and nanotubes. Special attention should be paid to very high specific electric conductivity, low weight, and high mechanical strength of carbon materials compared to copper and aluminum. Many centers in the world have recently performed intense conceptual works and studies on graphene/nanotube synthesis with copper and other metals to change their physical characteristics and improve their functional characteristics [6-10].

Table 1. Selected properties of copper, aluminum, and graphene [6-12].

\begin{tabular}{|c|c|c|c|c|}
\hline \multirow{2}{*}{ Parameter } & \multicolumn{2}{|c|}{ Traditional Materials } & \multicolumn{2}{|c|}{ Modern Materials } \\
\hline & Aluminium & Copper & Nanotubes & Graphene \\
\hline Melting point $\left[{ }^{\circ} \mathrm{C}\right]$ & 660 & 1083 & 4520 & 4620 \\
\hline Density $\left[\mathrm{g} / \mathrm{cm}^{3}\right]$ & 2.76 & 8.92 & $1.3-1.4$ & $1.1-1.5$ \\
\hline $\begin{array}{l}\text { Mobility of electrons, } \\
\qquad\left[\mathrm{cm}^{2} \mathrm{v}^{-1} \mathrm{~s}^{-1}\right]\end{array}$ & 1.2 & 4.33 & 10,000 & 15,000 \\
\hline Conductivity $[\mathrm{MS} / \mathrm{m}]$ & 36 & 58 & $280(1.5-5 \times \mathrm{Al})$ & $100(3 \times \mathrm{Al})$ \\
\hline Thermal conductivity $[\mathrm{W} / \mathrm{m} \cdot \mathrm{k}]$ & 200 & 400 & 3500 & $4840^{ \pm 440}-5300^{ \pm 480}$ \\
\hline Tensile strength [MPa] & 60-200 & $200-400$ & $11,000-63,000$ & 130,000 \\
\hline $\begin{array}{l}\text { Temperature coefficient of } \\
\text { resistance }\left[\mathrm{K}^{-1}\right]\end{array}$ & $4.0 \times 10^{-3}$ & $3.9 \times 10^{-3}$ & - & - \\
\hline Young Modulus [GPa] & 70 & 120 & 1000 & 1000 \\
\hline Atomic radius [pm] & 125 & 128 & 70 & 70 \\
\hline Lattice parameter $[\mathrm{pm}]$ & 404 & 360 & 142 & 142 \\
\hline
\end{tabular}

Nowadays, works are conducted globally towards implementing new solutions using composites of metals and different allotropic forms of carbon.

Special aluminum composites-carbon fibers-are used for carrier and conduction cores of power conductors. It helps improve the transmission capacity of conductors and 
reduce their weight and sagging, which are among the most important operating parameters of power lines. The Naval Research Laboratory in the USA developed high-resistance graphitized carbon fibers with excellent electrical characteristics. Works on copper-carbon fiber composites with improved mechanical strength are in progress. Nanotubes are another form of carbon used in power engineering. In 2010, in the USA, prof. Chen patented a Cu-CNT composite with almost $40 \%$ higher conductivity than copper [11]. Prof. Castro made Al-CNT wires with ca. 30\% higher conductivity than pure aluminum. Currently, leading global centers are working towards the development of such solutions. An advantage of graphene, which makes it stand out among other allotropic forms of carbon, is that it is not prone to form agglomerates (as nanotubes are) and has a much greater active blending area with the matrix than nanotubes. Moreover, global trends related to the application of carbon bring newer and cheaper technologies of acquiring this type of raw material. To that end, leading research and implementation centers work on developing methods of manufacturing and processing aluminum-graphene or copper-graphene composites. Such works are conducted in the following centers: US Army Benét Laboratories, Armaments Research Development and Engineering Center, Watervliet, Rice University, and Rensselaer Polytechnic Institute in the USA. Nowadays, the only application of graphene prepared for common use in the near future is in touch screens developed by the Korean Samsung [12-19].

Synthesis of graphene with aluminum or copper creates an opportunity to obtain new materials with previously unknown electrical and functional characteristics. There are different approaches and works on using different methods to develop such materials are in progress and include the following:

(a) Chemical synthesis-Covetic types of an atomic blend (blending by synthesis of liquid metal with graphene, under appropriate casting conditions) $[20,21]$.

(b) Electrochemical deposition of graphene on elements of copper or another material [22].

(c) Casting a mixture of liquid metal with graphene to a form facilitating further plastic processing to make wires with required characteristics (continuous-cast conductors as input material for further wire making can be the product of the process).

(d) Deposition of monoatomic carbon coats (graphene) using the CVD method on the surface of $\mathrm{Al}$ or $\mathrm{Cu}$ wires and their further plastic processing to form wires with required characteristics.

(e) Mechanical synthesis of $\mathrm{Al}$ powders coated with graphene or $\mathrm{Cu}$ powders coated with graphene to a form facilitating their further plastic processing to make wires with required characteristics [23-30].

There is a lot of research in the literature on the synthesis of graphene from metals. Authors of papers [20,21] presented detailed analysis development of copper covetic. Copper covetic is a material consisting of a copper matrix reinforced with the second phase, which is a chemical compound of carbon and copper forming a covalent bond between carbon and copper. It is assumed that the second phase is extremely fine-dispersive and is of nanometer dimensions. An advantage of such a bond is that it does not cleave during the material re-melting. This material exhibits excellent functional properties: a 50\% increase in tensile strength, a 50\% increase in thermal conductivity, and a $70 \%$ increase in electrical conductivity and fuse current over pure copper [20,21]. Wang et al. [31,32] presented the research results on the synthesis of the Al-C composite with a content of $0.3 \% \mathrm{wt}$. graphene. The addition of graphene led to an increase in the strength of the composite to the value of $249 \mathrm{MPa}$, which was an increase of $62 \%$ compared to pure aluminum (154 MPa). The authors of the work to produce the above-mentioned composite used a spherical aluminum powder ball milling process. To improve wettability, they used a $3 \%$ water solution of polyvinyl alcohol (PVA), thanks to which a hydrophilic membrane was formed on the surface of the aluminum particles. The obtained GO/Al composite powders were heatsoaked at $550{ }^{\circ} \mathrm{C}$ in an argon protective atmosphere for $2 \mathrm{~h}$ in order to decompose the PVA and reduce GO to a graphene nanosheets (GNS) sheet. The densification and consolidation of the powders consisted of pressing the powders, sintering at $580{ }^{\circ} \mathrm{C} / 2 \mathrm{~h}$, and hot extrusion 
at a temperature of $440{ }^{\circ} \mathrm{C}$. Interesting results of the synthesis of graphene with metals using HPT (High-Pressure Torsion), a technique involving the simultaneous twisting and squeezing of the material under high pressure, are presented in the article [33] by Y.Huang, P.Bazarnik, M.Lewandowska, and others. Researches produced nanocomposites by combining aluminum with graphene in the amount of $5 \%$, by mixing and pressing them at room temperature, and then by the HPT process in different temperatures (100 and $200{ }^{\circ} \mathrm{C}$ ) in different torsional stresses and numbers of twists was made. Most of the methods used to synthesize aluminum-carbon composites involve high-temperature processes, which may directly influence the oxidation of the metal matrix or the reactions that occur at the metal-carbon interface. The applied HPT method allows for strong plastic deformation, perfecting the grain and, as a result, improving its mechanical properties. Composites aired with this method obtained tensile strength at the level of 350, 340, and $290 \mathrm{MPa}$ and electrical conductivity at $25^{\circ} \mathrm{C}$ at the level of approx. $65 \%$ IACS-i.e., higher than pure aluminum.

Literature analysis shows that there are many methods of synthesizing aluminum and copper with graphene. It is difficult to say which one guarantees composites with the properties required for electrical applications, i.e., high electrical conductivity and high tensile strength. This is due to the problems associated with the poor wettability of graphene and copper or graphite and aluminum, the large difference in the density of copper and graphene, and the unstable quality of graphene currently available on the market [34-38].

\section{Materials and Methods}

The purpose of the study was to evaluate the synthesis of copper and graphene as well as aluminum and graphene and the formability of composites during the extrusion process. The tests involved the implementation of a powder synthesis of copper and aluminum powders with graphene.

\subsection{Raw Materials for Synthesis}

Mixtures of appropriate ratios of copper and aluminum powders and graphene were used to synthesize the powders. Graphene was produced in the Institute of Electronic Materials Technology in Warsaw within a project called "New wires made of metal-graphene composites with improved conductivity, intended for power conductors", implemented as a part of the Applied Research Programme by METGRAF Consortium. The Raman spectrum studies were performed with Renishaw inVia Confocal Raman Microscope - parameters: excitation (cw): lasers $532 \mathrm{~nm}, 633 \mathrm{~nm}, 1064 \mathrm{~nm}, 325 \mathrm{~nm}$, configuration: back-scattering, spatial resolution: 0.5 microns, resolution: about $1.5 \mathrm{~cm}^{-1}$, spectral range (Raman shift): $50 \mathrm{~cm}^{-1}-6000 \mathrm{~cm}^{-1}$, experimental temperature: ambient.

Figure 1 presents the results of SEM analysis and Raman spectrum of graphene used in the studies. Based on the analysis of the Raman spectrum, it was possible to determine the degree of deterioration of the produced layer, the stress of the layer, and the estimation of the number of layers. From the Raman spectrum (from the position of the 2D peak and its width, as well as from the ratio of the intensity of the $2 \mathrm{D}$ peaks to $\mathrm{G}$ ), it can be concluded that the sample consisted mainly of graphite flakes with a size of about $280 \mathrm{~nm}$, covered with a thin layer of graphene.

Figure 2 shows the results of SEM analysis of aluminum and copper powders (A and B) and selected points for chemical composition analysis by WDS method, compressed powder sample (C and D), single measurement area: $60 \mu \mathrm{m} \times 45 \mu \mathrm{m}$. 

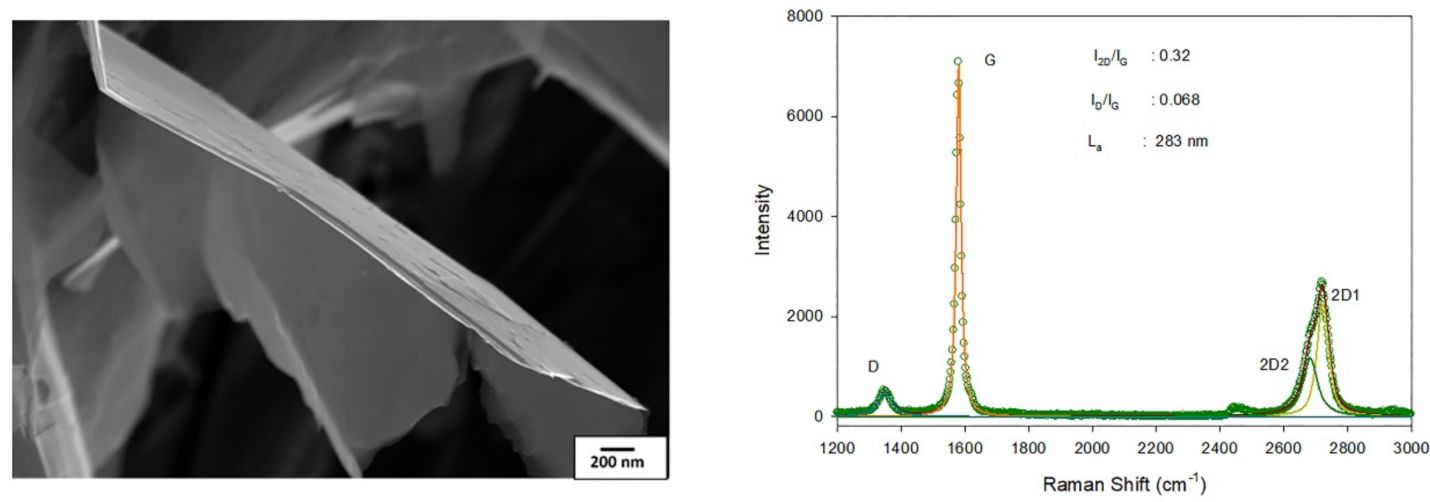

Figure 1. Flaked graphene, SEM, magnification: 25,000× (left), Raman spectrum (right).

ALUMINIUM POWDER

A

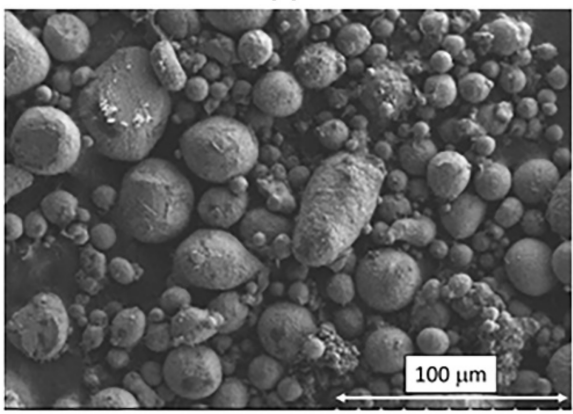

C

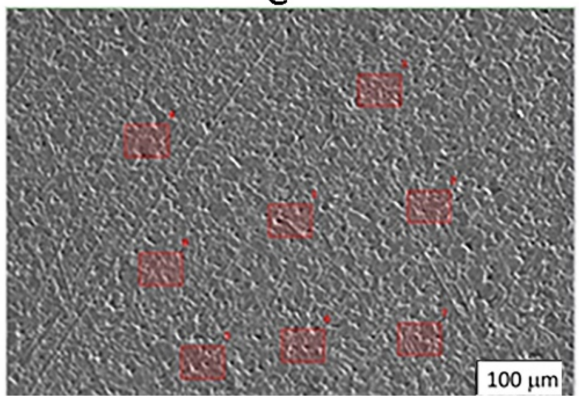

COPPER POWDER

$B$

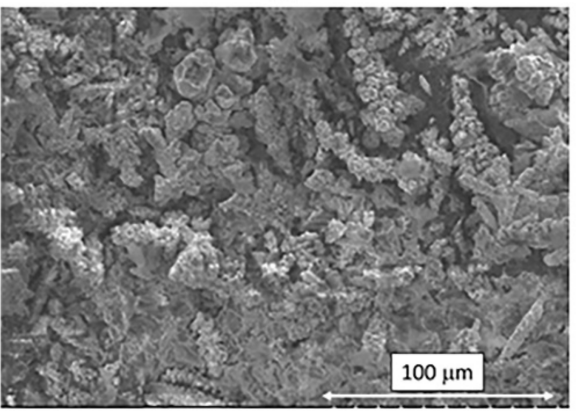

D

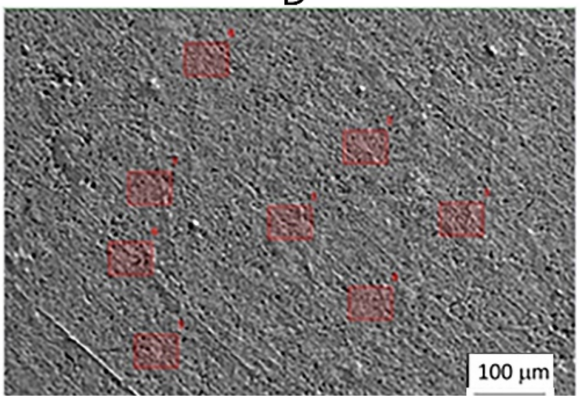

Figure 2. Aluminum and copper powder SEM images magnification $\times 500((\mathbf{A})-\mathrm{Al}$ powder, $(\mathbf{B})-\mathrm{Cu}$ powder) and compressed $\mathrm{Al}$ and $\mathrm{Cu}$ powder with selected points for chemical analysis by WDS (images (C,D)).

The chemical composition of $\mathrm{Al}$ and $\mathrm{Cu}$ powders selected for synthesis was tested on the JXA 8230 microanalyzer by Jeol (Tokyo, Japan). An accelerating voltage of $15 \mathrm{kV}$ was used, the electron beam current was $30 \mathrm{nA}$. The measurements were carried out using waveguide spectrometers (WDS, Oxford Instruments, High Wycombe, UK). The wavelength dispersion method enables a more accurate measurement of light elements. It is also characterized by a better detectability of elements and a higher resolution of spectral lines. Table 2 shows the results of the chemical composition analysis of powders selected for mechanical synthesis with graphene. 
Table 2. Chemical composition results of aluminum and copper powders (WDS method).

\begin{tabular}{|c|c|c|c|c|c|c|c|c|c|c|c|}
\hline \multirow{3}{*}{$\begin{array}{l}\text { Measuring } \\
\text { Point No }\end{array}$} & \multirow{2}{*}{\multicolumn{5}{|c|}{$\begin{array}{c}\text { Al. Powder } \\
\text { Chemical Composition, \%wt. }\end{array}$}} & \multicolumn{6}{|c|}{ Cu. Powder } \\
\hline & & & & & & \multirow{2}{*}{$\begin{array}{c}\text { Measuring } \\
\text { Point No }\end{array}$} & \multicolumn{5}{|c|}{ Chemical Composition, \%wt. } \\
\hline & $\mathrm{O}_{2}$ & $\mathrm{Cr}$ & $\mathrm{S}$ & $\mathrm{Fe}$ & Al & & $\mathrm{O}_{2}$ & $\mathrm{Cr}$ & $\mathrm{S}$ & $\mathrm{Fe}$ & $\mathrm{Cu}$ \\
\hline 1 & 0.819 & 0.024 & 0.003 & 0.118 & 98.4 & 1 & 0.355 & 0.000 & 0.006 & 0.000 & 99.2 \\
\hline 2 & 0.743 & 0.018 & 0.007 & 0.138 & 98.2 & 2 & 0.311 & 0.000 & 0.012 & 0.013 & 99.17 \\
\hline 3 & 0.868 & 0.000 & 0.004 & 0.11 & 98.19 & 3 & 0.296 & 0.034 & 0.000 & 0.000 & 99.07 \\
\hline 4 & 0.846 & 0.000 & 0.000 & 0.112 & 98.45 & 4 & 0.295 & 0.013 & 0.007 & 0.006 & 99.18 \\
\hline 5 & 0.721 & 0.000 & 0.000 & 0.127 & 98.43 & 5 & 0.24 & 0.003 & 0.000 & 0.000 & 99.42 \\
\hline 6 & 0.779 & 0.000 & 0.000 & 0.108 & 98.46 & 6 & 0.256 & 0.012 & 0.000 & 0.000 & 99.42 \\
\hline 7 & 0.876 & 0.011 & 0.005 & 0.114 & 98.53 & 7 & 0.234 & 0.000 & 0.000 & 0.028 & 99.28 \\
\hline 8 & 0.745 & 0.000 & 0.002 & 0.117 & 98.40 & 8 & 0.266 & 0.000 & 0.012 & 0.017 & 99.18 \\
\hline Average & 0.800 & 0.007 & 0.003 & 0.118 & 98.38 & Average & 0.282 & 0.008 & 0.005 & 0.008 & 99.24 \\
\hline
\end{tabular}

\subsection{Synthesis Parameters}

The synthesis involved mixing and compaction copper powders and aluminum powders with graphene, pressing them into compacts, and their further consolidation using the conventional extrusion method. The powder mixtures forming the $\mathrm{Al}-\mathrm{C}$ and $\mathrm{Cu}-\mathrm{C}$ composites were made according to the proportion of graphene addition: $0.5 \%$ and $1 \%$ by weight based on the weight of pure aluminum/copper powder. The mixing process was carried out using industrial and laboratory ball mills for 30 to $60 \mathrm{~min}$. The diagram of the composites and wires production process is shown in Figure 3.

COMPACTING

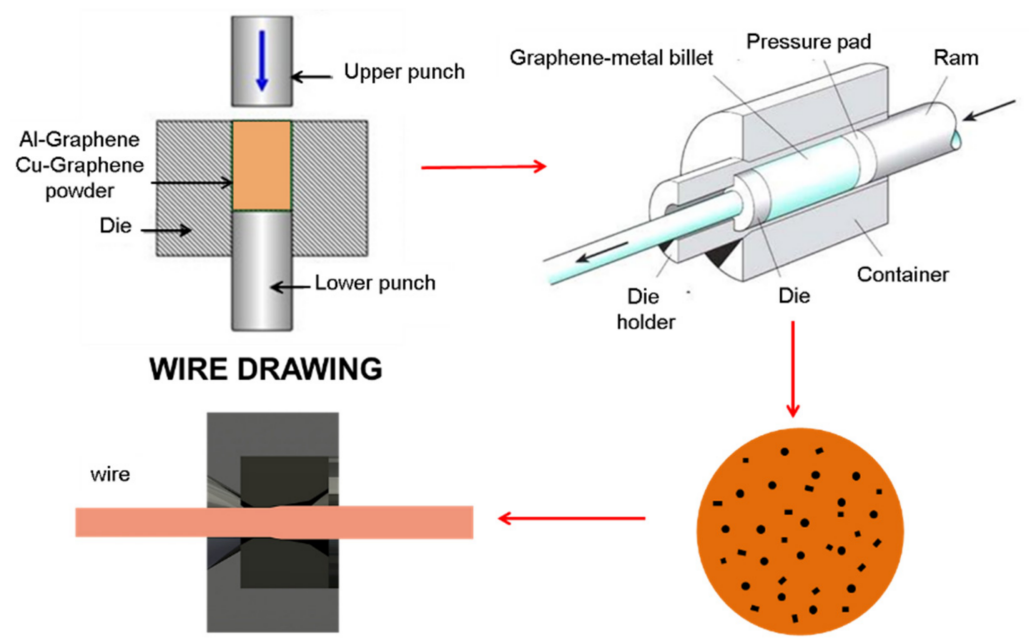

Figure 3. Diagram of wire production from $\mathrm{Cu}-\mathrm{C}$ and $\mathrm{Al}-\mathrm{C}$ composites (compaction, extrusion, and wiredrawing).

The criterion for selecting the mixing time of the powders was related to obtaining a homogeneous distribution of graphene in the volume of the metal matrix. Table 3 presents material parameters (graphene content in $\mathrm{Cu}-\mathrm{C}$ and $\mathrm{Al}-\mathrm{C}$ composites) and parameters of consolidating copper and aluminum powders with graphene (mixing process parameters and consolidation conditions). Figures 4 and 5 present composites of copper and aluminum powders with different graphene content produced using the method mentioned above. 
Table 3. Synthesis parameters of $\mathrm{Cu}-\mathrm{C}$ and $\mathrm{Al}-\mathrm{C}$ composites with different graphene content.

\begin{tabular}{|c|c|c|c|c|c|c|c|}
\hline \multirow{3}{*}{$\begin{array}{l}\text { Type of } \\
\text { Composite }\end{array}$} & \multicolumn{5}{|c|}{ Milling } & \multicolumn{2}{|c|}{ Consolidation } \\
\hline & \multirow{2}{*}{$\begin{array}{c}\text { Sample } \\
\text { No }\end{array}$} & \multirow{2}{*}{$\begin{array}{l}\text { Powder } \\
\text { Mass (g) }\end{array}$} & \multirow{2}{*}{$\begin{array}{l}\text { Graphene } \\
\text { Mass (g) }\end{array}$} & \multicolumn{2}{|c|}{ Graphene Content } & \multirow{2}{*}{$\frac{\text { Milling Time }}{\text { min }}$} & \multirow{2}{*}{$\begin{array}{c}\text { Pressure } \\
\text { atm }\end{array}$} \\
\hline & & & & \%wt. & \%vol. & & \\
\hline $\mathrm{Cu}-\mathrm{C}$ & 1 & 500 & 2.5 & 0.5 & 0.6 & $30-60$ & $30-50$ \\
\hline $\mathrm{Cu}-\mathrm{C}$ & 2 & 500 & 5 & 1 & 1.2 & $30-60$ & $30-50$ \\
\hline $\mathrm{Al}-\mathrm{C}$ & 3 & 100 & 0.5 & 0.5 & 0.6 & $30-60$ & $30-50$ \\
\hline $\mathrm{Al}-\mathrm{C}$ & 4 & 100 & 1 & 1 & 1.2 & $30-60$ & $30-50$ \\
\hline
\end{tabular}

a)

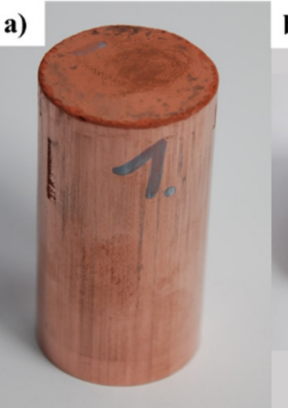

b)

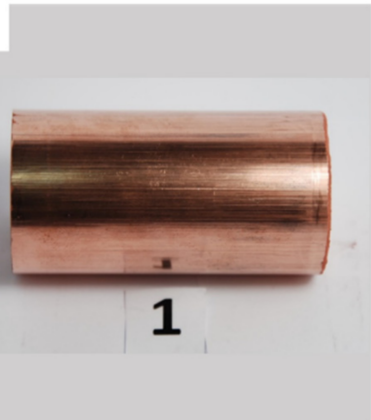

Figure 4. Copper-graphene composites (CUGRAF) obtained by the consolidation of powders: (a) view of the cross-sectional surface, $(\mathbf{b})$ view of the lateral surface.

a)

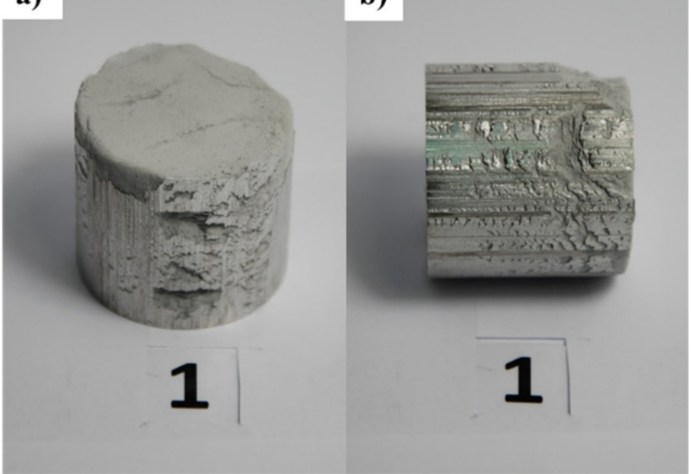

Figure 5. Aluminum-graphene (ALGRAF) obtained by the consolidation of powders (a) view of the cross-sectional surface, (b) view of the lateral surface).

In the case of ALGRAF composites, the increase in graphene content led to a deterioration of the compacting effect, which resulted in the production of moldings and presses with poor surface quality (see Figure 5).

Composites thus made were extruded using a special stand horizontal press with a rotating die. In the next step, extruded rods with a diameter of $4 \mathrm{~mm}$ were strained in $98 \%$ (strain hardening) by the wire drawing process, which helped obtain wires with a diameter of $1 \mathrm{~mm}$. Detailed parameters of the extrusion and wires drawing process are presented in Table 4. 
Table 4. Consolidation process parameters of CUGRAF and ALGRAF composites with different graphene content.

\begin{tabular}{|c|c|c|c|c|}
\hline \multirow[b]{2}{*}{ Type of Composite } & \multicolumn{2}{|c|}{ Extrusion Process } & \multirow{2}{*}{$\begin{array}{c}\text { Diameter } \\
\text { Rods after } \\
\text { Extrusion, }(\mathrm{mm})\end{array}$} & \multirow{2}{*}{$\begin{array}{c}\text { Diameter Wires after } \\
\text { Drawing Process, } \\
(\mathrm{mm})\end{array}$} \\
\hline & $\begin{array}{c}\text { Temperature, } \\
\left({ }^{\circ} \mathrm{C}\right)\end{array}$ & $\begin{array}{c}\text { Force, } \\
(\mathrm{kN})\end{array}$ & & \\
\hline ALGRAF (40 mm) & $200-400$ & 800 & 4 & 2 \\
\hline CUGRAF (40 mm) & $400-600$ & 1000 & 4 & 2 \\
\hline
\end{tabular}

\subsection{Methods of Testing the Properties of Composites}

Wires after the drawing process and rods after the extrusion process were tested for their mechanical, electrical, and structural properties. The tests of mechanical properties were carried out using the uniaxial tensile test. The mechanical properties of the samples were measured on a Zwick/Roell testing machine (Zwick, Ulm, Germany) with a maximum force range of $20 \mathrm{kN}$. The tests of electric properties were performed using the Thomson bridge. The maximum measuring resolution was $1 \mathrm{n} \Omega$, with measuring currents from $100 \mu$ to $10 \mathrm{~A}$. The accuracy class was $0.01 \%$. Microstructure tests were performed using a Scanning Electron Microscopy (Hitachi Model, Kasama, Japan) and Jeol JXA 8230 microanalyzer (EDS analysis). An accelerating voltage of $15 \mathrm{kV}$ was used, the electron beam current was $30 \mathrm{nA}$.

\section{Results and Discussion}

The main objective of the research was to answer whether the Al-Graphene and $\mathrm{Cu}-\mathrm{Graphene}$ composites produced a guaranteed homogeneous structure and chemical composition throughout the entire volume of the composite.

Figures 6 and 7 present the results of EDS analysis of graphene decomposition in the matrix of copper and aluminum extruded bars with a graphene content of $1 \%$ by weight.
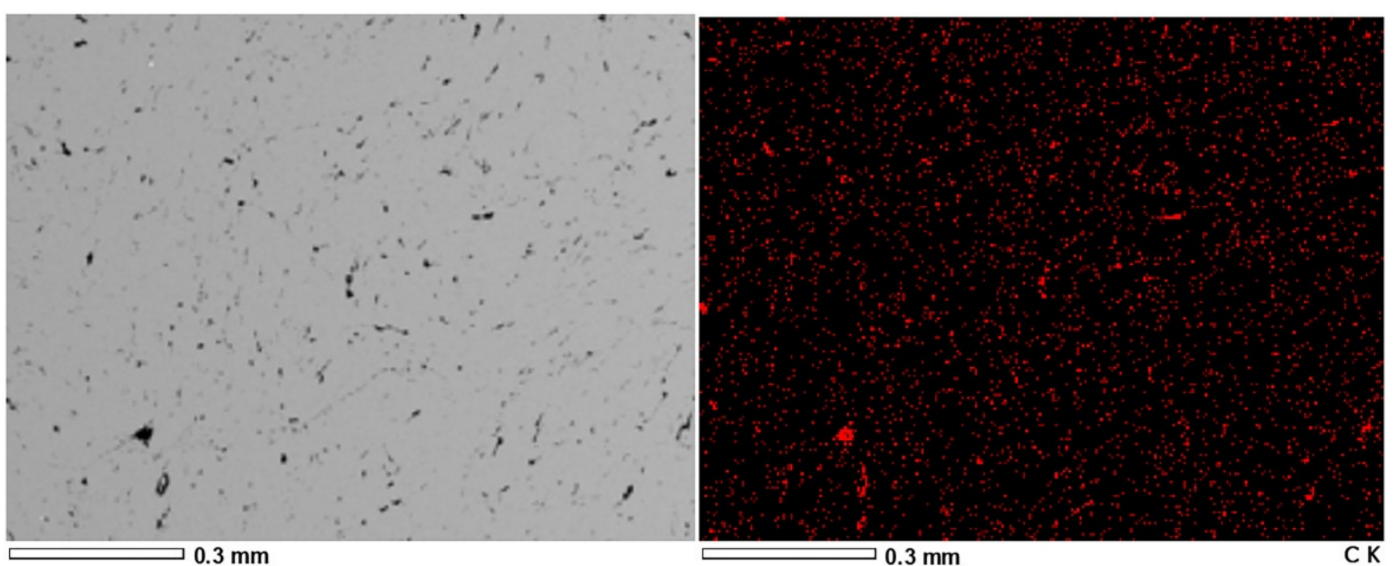

Figure 6. EDS analysis of graphene distribution in sample no 1-rods after the extrusion of CUGRAF composites ( $1 \%$ by weight of graphene).

Based on the research, it was found that the composites obtained both as a result of plastic consolidation (extrusion process) of ALGRAF and CUGRAF showed a homogeneous distribution of graphene in the entire volume, which guarantees a homogeneous distribution of properties along the length of the wires produced.

Table 5 shows the results of the tests of mechanical and electrical properties produced for further processing. 


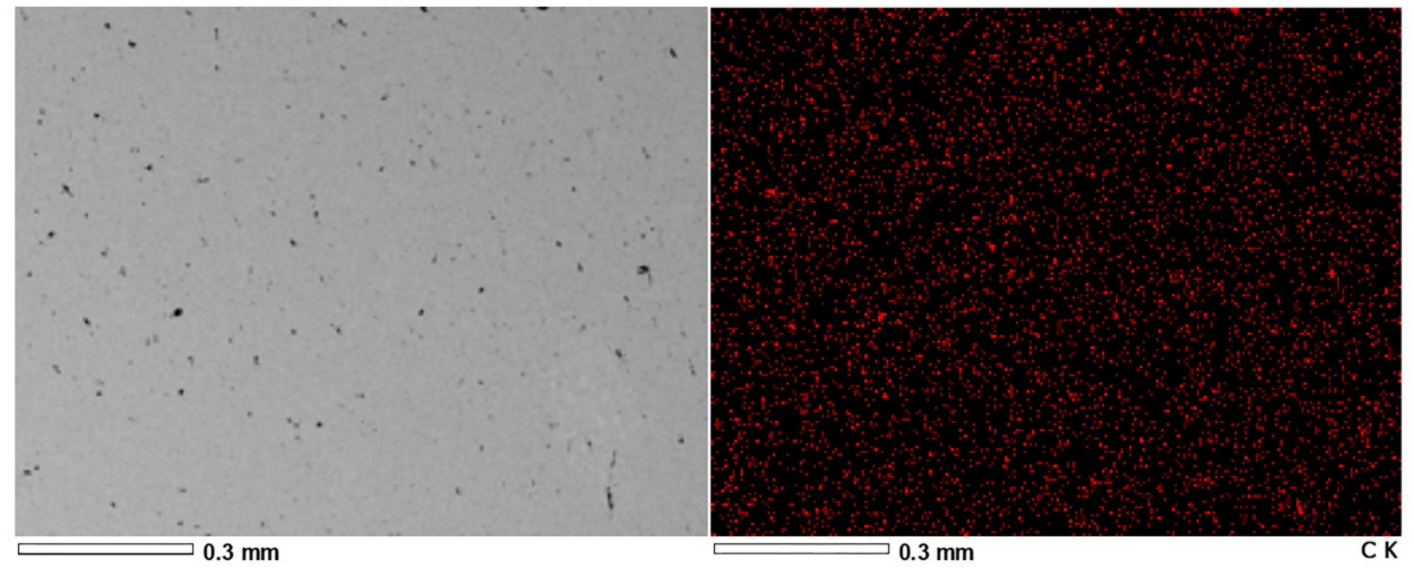

Figure 7. EDS analysis of graphene distribution in sample no 3 (rods after the extrusion of ALGRAF composites- $1 \%$ by weight of graphene.

Table 5. Mechanical and electrical properties of the CUGRAF and ALGRAF rods after the extrusion process.

\begin{tabular}{ccccc}
\hline Sample No & $\begin{array}{c}\text { Ultimate Tensile Strength } \\
\text { (UTS), } \\
(\mathbf{M P a})\end{array}$ & $\begin{array}{c}\text { Yield Stress } \\
\text { (YS), } \\
(\mathbf{M P a})\end{array}$ & $\begin{array}{c}\mathbf{A}_{\mathbf{1 0 0}} \\
\mathbf{( \% )}\end{array}$ & $\begin{array}{c}\text { Resistivity 20 } \\
(\mathbf{n} \boldsymbol{\Omega} \mathbf{C})\end{array}$ \\
\hline 1 & 211 & 158 & 11.3 & 17.6 \\
\hline 2 & 221 & 162 & 10.2 & 17.9 \\
\hline 3 & 117 & 98 & 3.1 & 28.16 \\
\hline 4 & 128 & 114 & 3.2 & 28.84 \\
\hline Pure $\mathrm{Cu}$ & 208 & 154 & 25.0 & 17.2 \\
\hline Pure $\mathrm{Al}$ & 123 & 100 & 5.7 & 27.31 \\
\hline
\end{tabular}

One can observe that the higher content of graphene in CUGRAF and ALGRAF composites significantly reduced the plasticity of the material. Nevertheless, no significant differentiation of the tensile strength was observed, and the values of 200-250 MP (for $\mathrm{Cu}-\mathrm{C}$ ) and 140-150 MPa (Al-C) for the majority of materials were reached. An analysis of the impact of graphene content on electrical properties of the studied composites at different processing stages revealed slightly higher resistivity values as compared to the base material, i.e., pure copper and pure aluminum. This was the evidence of the probable presence of graphene material in a form not linked with the copper or aluminum matrix. Additionally, the lack of reduction in resistivity could result from imperfect consolidation and processing of the composites.

After the tensile tests, wire fracture was analyzed by SEM. Photos of fractures of wires made of ALGRAF and CUGRAF composite are presented in Figure 8. The shape of the fractures in practically all cases is similar to the brittle fractures. There are no plastically deformed areas. The general shape of the fractures in all cases is similar to the brittle fractures. There are no plastically deformed areas-typical for aluminum and copper wires. A detailed analysis showed delamination of the material in the case of ALGRAF composite wires with the highest graphene content. The above phenomenon may result from the lack of good wettability of graphene to aluminum and, consequently, the lack of a strong bond of graphene with the aluminum matrix. 
Table 6. Mechanical and electrical properties of the CUGRAF and ALGRAF wires after the drawing process.

\begin{tabular}{ccccc}
\hline Sample No & $\begin{array}{c}\text { Ultimate Tensile Strength } \\
\text { (UTS), } \\
(\mathbf{M P a})\end{array}$ & $\begin{array}{c}\text { Yield Stress } \\
\text { (YS), } \\
(\mathbf{M P a})\end{array}$ & $\begin{array}{c}\mathbf{A}_{\mathbf{1 0 0}} \\
\mathbf{( \% )}\end{array}$ & $\begin{array}{c}\text { Resistivity 20 } \\
(\mathbf{n} \boldsymbol{\Omega} \mathbf{C})\end{array}$ \\
\hline 1 & 373 & 363 & 2.20 & 18.04 \\
\hline 2 & 390 & 376 & 2.60 & 18.20 \\
\hline 3 & 194 & 187 & 1.52 & 28.65 \\
\hline 4 & 209 & 114 & 2.19 & 28.96 \\
\hline Pure $\mathrm{Cu}$ & 437 & 430 & 3.20 & 17.54 \\
\hline Pure $\mathrm{Al}$ & 184 & 179 & 1.88 & 28.53 \\
\hline
\end{tabular}

Fracture of wires after tensile test

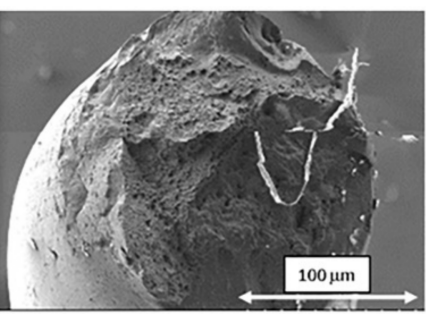

Cu powder wire

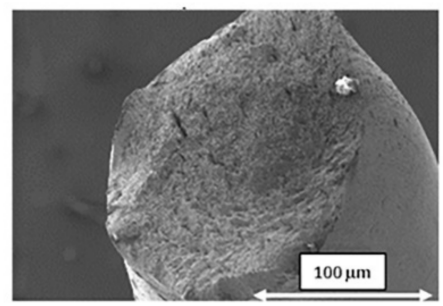

Al powder wire

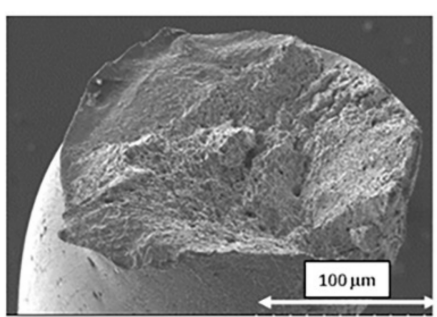

Sample no 1

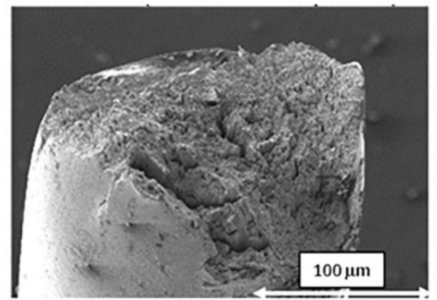

Sample no 3

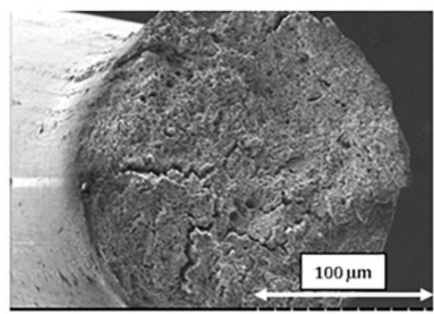

Sample no 2

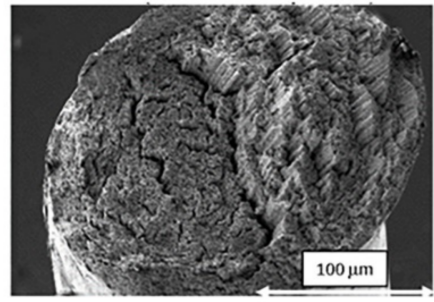

Sample no 4

Figure 8. SEM image of wires fracture after tensile test according to Table 6, magnification $\times 100$.

Figures 9 and 10 show graphs illustrating the relationship between the (UTS-Ultimate Tensile Strength) and resistivity of the rods obtained in the extrusion process and wires obtained in the wiredrawing process.

Based on the relations presented in Figures 9 and 10, it was found that the differentiation of the graphene content in copper leads to different UTS values. It was found the above relationship is close to linear. The highest increase in UTS was found in composites of pure $\mathrm{Al}$ and $\mathrm{Cu}$ powders, and the lowest in composites containing $1 \%$ graphene.

On the other hand, in the case of extruded rods, it has been observed that the addition of graphene to the $\mathrm{Al}$ matrix and $\mathrm{Cu}$ matrix leads to an increase in resistivity (a decrease in electrical conductivity). Interestingly, in the case of aluminum-graphene rods and wires, the differentiation of the resistivity value was concluded for various graphene content. Higher resistivity values of wires compared to rods are an effect of dislocation density increasing. While similar Al-C wires resistivity values-regardless of the graphene contentresults from the increase in their density, an additional effect was compacting due to cold deformation (the deformation value is at the level of $96 \%$ ). In the case of copper-graphene composites, this situation does not exist. The differentiation of the resistivity value for $\mathrm{Cu}-\mathrm{C}$ rods after extrusion and for wires after the drawing process is similar. 


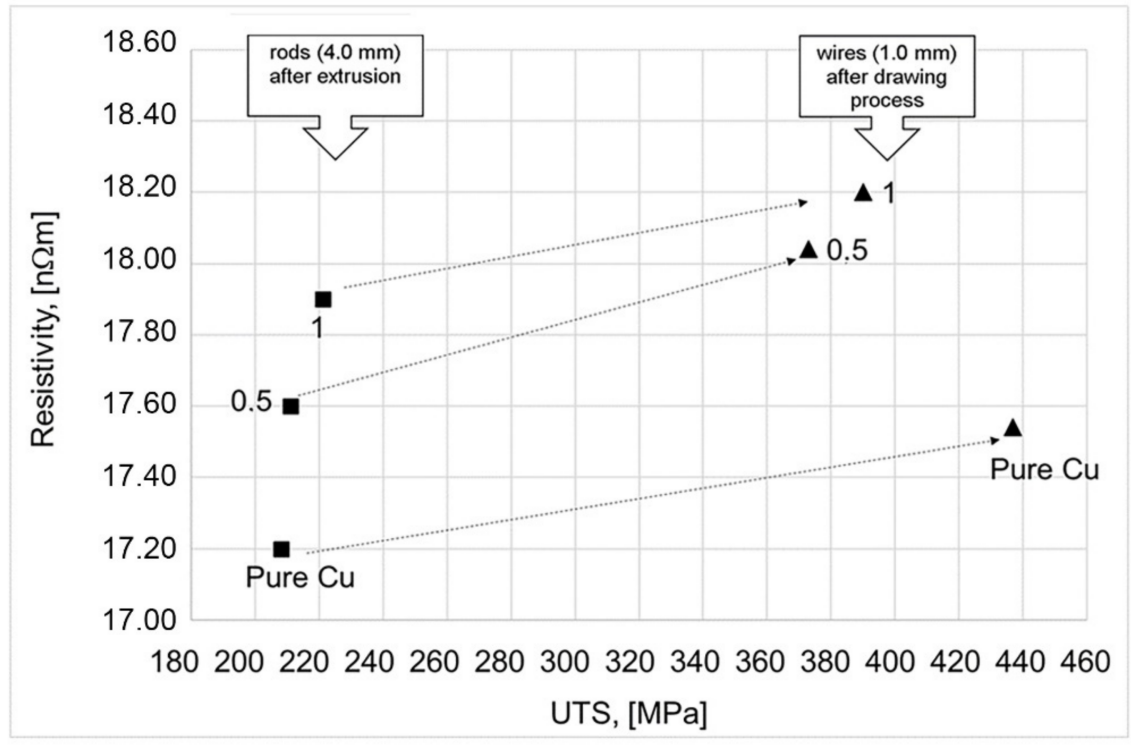

Figure 9. Relationship between UTS and resistivity of CUGRAF composite after extrusion and after wire drawing process (sample no 1 and 2 and pure $\mathrm{Cu}$ ).

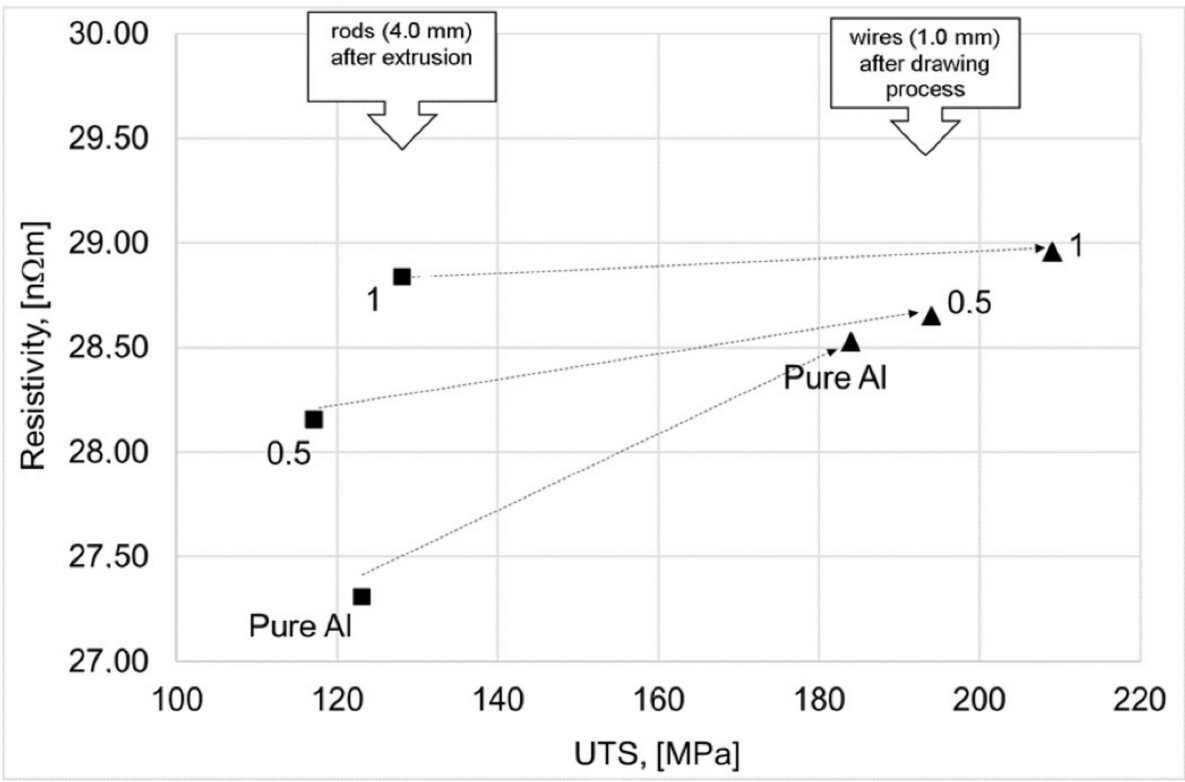

Figure 10. Relationship between UTS and resistivity of ALGRAF composite after extrusion and after wire drawing process (samples no 3 and 4 and pure $\mathrm{Al}$ ).

The wires obtained by the laboratory drawing process did not show any lower than standard resistivity at room temperature compared to the reference materials (Cu-ETP or pure Al.-see Table 1). The lack of a decrease in the electrical resistivity of composites is related to the high resistivity (to low electrical conductivity) of the graphene used and the synthesis method. One of the major difficulties in the mechanical synthesis of $\mathrm{Cu}-\mathrm{C}$ and Al-C composites is the poor wettability of copper and aluminum with graphene. Perhaps using a sintering process would make it possible to obtain better results related to the electrical properties.

\section{Conclusions}

Based on the results of experimental research, it was found that: 
1. As a result of the mechanical synthesis process consisting of mixing and compacting (without sintering), Al-C and $\mathrm{Cu}-\mathrm{C}$ composites with homogeneous carbon distribution were obtained.

2. The results of the drawing process showed good deformability of composite wires in the drawing process. At the same time, a limited ductility was found, which is expressed by a lower total deformability of these materials compared to traditional materials. The above fact results from the significantly lower plasticity of composite wires.

3. The addition of graphene to aluminum and copper results in an increase in resistivity and strength

4. The addition of graphene to copper and aluminum results in a different type of strain hardening during the wiredrawing process. The addition of graphene to aluminum leads to greater strain hardening (increasing UTS: pure Al-49.6\%, Al-C0.5\% wt.$65.8 \%, \mathrm{Al}-\mathrm{C} 1 \% \mathrm{wt} .-63.3 \%$ ). On the other hand, in the case of $\mathrm{Cu}-\mathrm{C}$ composites, the addition of graphene resulted in a lower strain hardening in the drawing process (increasing of UTS: pure $\mathrm{Cu}-110.1 \%$, Cu-C0.5\% wt. $-76.8 \%, \mathrm{Al}-\mathrm{C} 1 \% \mathrm{wt}-76.5 \%$ ). The different types of strain hardening result from a different mechanism of graphene interaction on $\mathrm{Cu}$ and $\mathrm{Al}$.

5. The obtained results showed that it is possible to produce wires from composites based on aluminum/copper powders with the addition of graphene in the core of the wires, which can be a component of overhead power cables.

Author Contributions: Conceptualization, T.K. and A.M.; methodology, P.K.; validation, P.K., G.K. and M.G.; formal analysis, B.S.; investigation, E.S.-S., K.K., P.K., G.K. and M.G.; writing-original draft preparation, B.S.; writing-review and editing, A.K.; visualization, E.S.-S.; supervision, T.K. and A.M. All authors have read and agreed to the published version of the manuscript.

Funding: This research was funded by The National Centre for Research and Development, New wires of metal-graphene composites with improved conductivity, intended for power conductors, grant number PBS2/B5/30/2013.

Institutional Review Board Statement: Not applicable.

Informed Consent Statement: Not applicable.

Data Availability Statement: Data sharing is not applicable.

Acknowledgments: The authors extend their appreciation to the The National Centre for Research and Development in Poland.

Conflicts of Interest: The authors declare no conflict of interest.

\section{References}

1. McConnell, B.W. Applications of high temperature superconductors to direct current electric power transmission and distribution. IEEE Trans. Appl. Supercond. 2005, 15, 2142-2145. [CrossRef]

2. Snider, E.; Dasenbrock-Gammon, N.; McBride, R.; Debessai, M.; Vindana, H.; Vencatasamy, K.; Lawler, K.V.; Salamat, A.; Dias, R.P. Room-temperature superconductivity in a carbonaceous sulfur hydride. Nature 2020, 586, 373-377. [CrossRef]

3. Tiwari, S.K.; Sahoo, S.; Wang, N.; Huczko, A. Graphene research and their outputs: Status and prospect. J. Sci. Adv. Mater. Devices 2020, 5, 10-29. [CrossRef]

4. Madurani, K.A.; Suprapto, S.; Machrita, N.I.; Bahar, S.L.; Illiya, W.; Kurniawan, F. Progress in Graphene Synthesis and its Application: History, Challenge and the Future Outlook for Research and Industry. ECS J. Solid State Sci. Technol. 2020, $9,093013$. [CrossRef]

5. Su, J.; Teng, J. Recent progress in graphene-reinforced aluminum matrix composites. Front. Mater. Sci. 2021, 15, 79-97. [CrossRef]

6. Hidalgo-Manrique, P.; Lei, X.; Xu, R.; Zhou, M.; Kinloch, I.A.; Young, R.J. Copper/graphene composites: A review. J. Mater. Sci. 2019, 54, 12236-12289.

7. Hidalgo-Manrique, P.; Yan, S.; Lin, F.; Hong, Q.; Kinloch, I.A.; Chen, X.; Young, R.J.; Zhang, X.; Dai, S. Microstructure and mechanical behavior of aluminium matrix composites reinforced with graphene oxide and carbon nanotubes. J. Mater. Sci. 2017, 52, 13466-13477. [CrossRef]

8. Lee, J.H.; Park, S.J.; Choi, J.W. Electrical Property of Graphene and Its Application to Electrochemical Biosensing. Nanomaterials 2019, 9, 297. [CrossRef] [PubMed] 
9. Cabanas-Moreno, J.G.; Morales-Hernandez, J. Microstructural Characterization of Copper-Carbon Composites. In 2002 Annual Congress of the Mexican Academy of Materials Science: Advanced Structural Materials Symposium; Sociedad Mexicana de Materiales: Cancun, Quintana Roo, Mexico, 2002.

10. Yamane, T.; Okubo, H.; Hisayuki, K.; Oki, N.; Konishi, M.; Komatsu, M.; Minamino, Y.; Koizumi, Y.; Kiritani, M.; Kim, S.J. Solid solubility of carbon in copper mechanically alloyed. J. Mater. Sci. Lett. 2001, 20, 259-260. [CrossRef]

11. Electrochemical-Codeposition Methods for Forming Carbon Nanotube Reinforced Metal Composites. U.S. Patent 20100122910A1, 20 May 2010.

12. Copper-Carbon Composition. Patent WO 2011/005494A1, 13 January 2011.

13. Novoselov, K.S.; Geim, A.K.; Morozov, S.V.; Jiang, D.; Zhang, Y.; Dubonos, S.V.; Grigorieva, I.V.; Firsov, A.A. Electric field effect in atomically thin carbon films. Science 2004, 306, 666-669. [CrossRef] [PubMed]

14. Geim, A.; Novoselov, K. Graphene calling. Nat. Mater. 2007, 6, 169.

15. Geim, A.K. Graphene. Science 2009, 324, 1530-1534. [CrossRef]

16. Sutter, P.W.; Flege, J.I.; Sutter, E.A. Epitaxial graphene on ruthenium. Nat. Mater. 2008, 7, 406-411. [CrossRef]

17. Imandoust, A.; Barrett, C.D.; Al-Samman, T.; Inal, K.a.; El Kadiri, h.A. A review on the effect of rare-earth elements on texture evolution during processing of magnesium alloys. J. Mater. Sci. 2017, 52, 1-29. [CrossRef]

18. Khanna, V.; Kumar, V.; Bansal, S.A. Mechanical properties of aluminium-graphene/carbon nanotubes (CNTs) metal matrix composites: Advancement, opportunities and perspective. Mater. Res. Bull. 2021, 38, 111224. [CrossRef]

19. An, Z.; Li, J.; Kikuchi, A.; Wang, Z.; Jiang, Y.; Ono, T. Mechanically strengthened graphene-Cu composite with reduced thermal expansion towards interconnect applications. Microsyst. Nanoeng. 2019, 5, 50. [CrossRef]

20. Bakir, M.; Jasiuk, I. Novel metal-carbon nanomaterials: A review on covetics. Adv. Mater. Lett. 2017, 8, 884-890. [CrossRef]

21. Balachandran, U.; Ma, B.; Dorris, S.E.; Koritala, R.E.; Forrest, D.R. Nanocarbon-Infused Metals: A New Class of Covetic Materials for Energy Applications. Adv. Mater. Sci. Environ. Energy Technol. VI Ceram. Trans. 2017, 262, 205-218.

22. Pavithra, C.L.; Sarada, B.V.; Rajulapati, K.V.; Rao, T.N.; Sundararajan, G. A New Electrochemical Approach for the Synthesis of Copper-Graphene Nanocomposite Foils with High Hardness. Sci. Rep. 2014, 4, 4049. [CrossRef] [PubMed]

23. Bartolucci, S.F.; Paras, J.; Rafiee, M.A.; Rafiee, J.; Lee, S.; Kapoor, D.; Koratkar, N. Graphene-aluminum nanocomposites. Mater. Sci. Eng. A 2011, 27, 7933-7937. [CrossRef]

24. Zhang, J.; Chen, Z.; Zhao, J.; Jiang, Z. Microstructure and mechanical properties of aluminium-graphene composite powders produced by mechanical milling. Mech. Adv. Mater. Mod. Processes 2018, 4, 4. [CrossRef]

25. Liu, J.; Khan, U.; Coleman, J.; Fernandez, B.; Rodriguez, P.; Naher, S.; Brabazon, D. Graphene oxide and graphene nanosheet reinforced aluminium matrix composites: Powder synthesis and prepared composite characteristics. Mater. Des. 2016, 94, 87-94. [CrossRef]

26. Chen, F.; Gupta, N.; Behera, R.K.; Rohatgi, P.K. Graphene-Reinforced Aluminum Matrix Composites: A Review of Synthesis Methods and Properties. JOM 2018, 70, 837-845. [CrossRef]

27. Kováčik, J.; Emmer, Š.; Bielek, J. Thermal conductivity of Cu-graphite composites. Int. J. Therm. Sci. 2015, 90, 298-302. [CrossRef]

28. Nazeer, F.; Ma, Z.; Gao, L.; Malik, A.; Abubaker Khan, M.; Wang, F.; Li, H. Effect of processing routes on mechanical and thermal properties of copper-graphene composites. Mater. Sci. Technol. 2019, 35, 1770-1774. [CrossRef]

29. Randviir, E.P.; Brownson, D.A.C.; Banks, C.E. A decade of graphene research: Production, application and outlook. Mater. Today 2014, 17, 426-432. [CrossRef]

30. Wang, J.; Li, Z.; Fan, G.; Pan, H.; Chen, Z.; Zhang, D. Reinforcement with graphene nanosheets in aluminum matrix composites Scr. Mater. 2012, 66, 594-597. [CrossRef]

31. Wang, J.; Guo, L.N.; Lin, W.M.; Chen, J.; Liu, C.L.; Zhang, S.; Zhen, T.T. Effect of the graphene content on the microstructures and properties of graphene/aluminum composites. New Carbon Mater. 2019, 34, 275-285. [CrossRef]

32. Ke, Q.; Wang, J. Graphene-based materials for supercapacitor electrodes-A review composites. J. Mater. 2016, 2, 37-54.

33. Huang, Y.; Bazarnik, P.; Wan, D.; Luo, D.; Pereira, P.H.R.; Lewandowska, M.; Yao, J.; Hayden, B.E.; Langdon, T.G. The fabrication of graphene-reinforced Al-based nanocomposites using high-pressure torsion. Acta Mater. 2019, 164, 499-511. [CrossRef]

34. Jiang, R.; Zhou, X.; Fang, Q.; Liu, Z. Copper-graphene bulk composites with homogeneous graphene dispersion and enhanced mechanical properties, Mater. Sci. Eng. A 2016, 654, 124-130. [CrossRef]

35. Zhu, Y.; Ji, H.; Cheng, H.M.; Ruoff, R.S. Mass production and industrial applications of graphene materials, Natl. Sci. Rev. 2018, 5, 90-101.

36. Rana, R.S.; Purohit, R.; Das, S. Review of recent studies in Al matrix composites. Int. J. Sci. Eng. Res. 2012, 3. Available online: https:/ / www.ijser.org/researchpaper/Review-of-recent-Studies-in-Al-matrix-composites.pdf (accessed on 11 January 2022).

37. Rajeshkumar, R.; Udhayabanu, V.; Srinivasan, A.; Ravi, K.R. Microstructural evolution in ultrafine grained Al-graphite composite synthesized via combined use of ultrasonic treatment and friction stir processing, J. Alloy. Compd. 2017, 726, 358-366. [CrossRef]

38. Chen, F.; Ying, J.; Wang, Y.; Du, S.; Liu, Z.; Huang, Q. Effects of graphene content on the microstructure and properties of copper matrix composites. Carbon 2016, 96, 836-842. [CrossRef] 